\title{
Papel actual de la circuncisión neonatal
}

\section{Present Role of Neonatal Circumcision}

\author{
Johanna Ovalle D. ${ }^{1}$ \\ 1 Urologa, Fundación Universitaria Sanitas, Bogotá, Colombia \\ Urol Colomb 2018;27:300-302.
}

La circuncisión neonatal ha sido un tema ampliamente debatido durante décadas, eso se refleja en las estadísticas que demuestran una reducción en su uso por ejemplo, en Canadá, del 51\% al 31\% de 1970 al 2007, en los Estados Unidos del 60\% al 50\% de 1999 al 2010, al igual que en el Reino Unido, donde su descenso ha sido del 2,6 al 2,1/1000 nacidos vivos desde 1997 al $2004 .^{1}$ En nuestro país, se desconocen los datos al respecto.

Actualmente la posición de las autoridades en salud a nivel internacional han reconocido su beneficio en cuanto a la prevención de la infección de vías urinarias (IVU), sintomáticas (febriles) especialmente en niños menores de 3 meses, en quienes es 10 veces más frecuente en pacientes sin circuncisión vs con circuncisión $(20,1$ vs 2,4$)$, sin embargo, esa brecha disminuye en niños de 6 a 12 meses $(7,3 \text { vs } 0,3 \%)^{2}$ Estudios demuestran que en niños con antecedente de IVU el número necesario para tratar (NNT) es de $4,2,{ }^{3}$ mientras que otros estudios demuestran que en niños sanos el NNT se eleva hasta $111 .^{4}$

En cuanto a los pacientes con comorbilidades urológicas reconocidas, se ha demostrado que, en niños con reflujo vesico ureteral de alto grado, presentan el doble de alteraciones nuevas en el DMSA sin circuncisión vs con circuncisión (10,4\% vs 5,2\%) aunque eso no necesariamente se demuestre con IVU sintomáticas ${ }^{5}$; en pacientes con valvas de uretra posterior se logra una reducción del $83 \%$ de IVU, con un NNT calculado de $1^{6}$; y en pacientes con hidronefrosis secundaria a la estrechez de la unión pieloureteral, se encontró la no circuncisión como un factor de riesgo para IVU (OR 3,63; 95\% CI 1,2-11,2). ${ }^{7}$ Los hallazgos que justifican ese efecto favorable se debe a la prevención de colonización bacteriana periuretral y glandular, con una reducción del medio prepucial enriquecido para el crecimiento bacteriano, especialmente anaerobios, que perpetúan procesos inflamatorios crónicos. ${ }^{1}$

published online June 11, 2018
DOI https://doi.org/ 10.1055/s-0038-1660444 ISSN 0120-789X. eISSN 2027-0119.
Address for correspondence Johanna Ovalle D., MD, Fundación Universitaria Sanitas, Calle 23 No. 66-46, Bogotá, Colombia (e-mail: joha_o@hotmail.com; johaod@gmail.com).

Basados en esos datos, las asociaciones urológicas canadiense, ${ }^{1}$ americana ${ }^{8,9}$ y británica, ${ }^{10}$ respaldan la realización de circuncisión neonatal en esos pacientes específicos, con una amplia y clara discusión de los riesgos con los padres o responsables. Reconociendo que las complicaciones se presentan aproximadamente $2 \%$ de los casos, incluyendo infección (1,5\%), sangrado (1,3\%), reintervención quirúrgica $(0,5 \%)$, estrechez meatal (2-11\%), entre las más frecuentes. Ellas dependen de la pericia del cirujano, elección de la técnica, edad del paciente, entre otros. Estudios demuestran que por cada complicación se logran prevenir 6 IVU. ${ }^{1}$

En cuanto a la edad ideal para realizarla, se logró demostrar una mejor tolerancia al dolor en los primeros 8 días de vida, realizando la técnica bajo anestesia local, que se puede realizar con bloqueo peneano dorsal o bloqueo anular (nivel 1-2, grado A), asociado a anestésicos tópicos, soluciones de sucrosa y glucosa, reduciendo el riesgo de anestesia general. ${ }^{1,11}$

Desde otro punto de vista, la organización mundial de la salud (OMS), desde 2007 recomienda la circuncisión de manera universal como una medida de prevención del VIH y SIDA, ${ }^{12}$ sin embargo, los estudios que resaltan un factor protector en la transmisión de la enfermedad (con [RR] 0,42; $95 \% \mathrm{Cl} 0,34-0,54 \%)^{13}$ se llevaron a cabo en países africanos con altos índices de prevalencia de la enfermedad (4,2\% para el 2016), mientras que la prevalencia en nuestro país es más baja (0,5\% para 2016). Adicionalmente, esa medida solo es preventiva para hombres heterosexuales que corresponden aproximadamente al 30\% de la población afectada. ${ }^{12}$ Motivo por el que no es una justificación aceptada para realizar la circuncisión neonatal preventiva; al igual que otros aspectos como en prevención de enfermedades de transmisión sexual, VPH y cáncer de pene, en donde se ha demostrado que el incentivar el uso de condón, sexualidad responsable, consulta adolescente, vacunación y otros métodos de prevención son más costo efectivos que la circuncisión. ${ }^{1}$
Copyright (c) 2018, Sociedad Colombiana License terms de Urología. Publicado por Thieme Revinter Publicações Ltda., Rio de Janeiro, Brazil. Todos los derechos reservados. 


\section{Bibliografía}

1 Dave S, Afshar K, Braga LH, Anderson P. Canadian Urological Association guideline on the care of the normal foreskin and neonatal circumcision in Canadian infants (full version). Can Urol Assoc J 2018;12(02):E76-E99

2 Shaikh N, Morone NE, Bost JE, Farrell MH. Prevalence of urinary tract infection in childhood: a meta-analysis. Pediatr Infect Dis J 2008;27(04):302-308

3 Jagannath VA, Fedorowicz Z, Sud V,Verma AK, Hajebrahimi S. Routine neonatal circumcision for the prevention of urinary tract infections in infancy. Cochrane Database Syst Rev 2012;11:CD009129

4 Singh-Grewal D, Macdessi J, Craig J. Circumcision for the prevention of urinary tract infection in boys: a systematic review of randomised trials and observational studies. Arch Dis Child 2005;90(08):853-858. Doi: 10.1136/adc.2004.049353

5 Alsaywid BS, Saleh H, Deshpande A, Howman-Giles R, Smith GH. High grade primary vesicoureteral reflux in boys: long-term results of a prospective cohort study. J Urol 2010;184(4, Suppl) 1598-1603

6 Mukherjee S, Joshi A, Carroll D, Chandran H, Parashar K, McCarthy L. What is the effect of circumcision on risk of urinary tract infection in boys with posterior urethral valves? J Pediatr Surg 2009;44(02):417-421

7 Zareba P, Lorenzo AJ, Braga LH. Risk factors for febrile urinary tract infection in infants with prenatal hydronephrosis: comprehensive single center analysis. J Urol 2014;191(5, Suppl):1614-1618. Doi: 10.1016/j.juro.2013.10.035

8 Circumcision, policy statements; The American Urological Association, Inc. ${ }^{\circledR}$ (AUA), May 2017 (Revised); www.auanet.org/ guidelines/circumcision

9 American Academy of Pediatrics Task Force on Circumcision. Male circumcision. Pediatrics 2012;130(03):e756-e785. Doi: 10.1542/ peds.2012-1990

10 The law and ethics of male circumcision Guidance for doctors June 2006. British Medical Association. www.bma.org.uk

11 Brady-Fryer B, Wiebe N, Lander JA. Pain relief for neonatal circumcision. Cochrane Database Syst Rev 2004;(04):CD004217 12 http://www.who.int/gho/hiv/en/

13 Weiss HA, Quigley MA, Hayes RJ. Male circumcision and risk of HIV infection in sub-Saharan Africa: a systematic review and metaanalysis. AIDS 2000;14(15):2361-2370. Doi: 10.1097/00002030200010200-00018 
